Article

\title{
Risk Assessment of Drought, Based on IDM-VFS in the Nanpan River Basin, Yunnan Province, China
}

\author{
Junfei Chen ${ }^{1,2,3, *}$ (D) , Menghua Deng ${ }^{2}$ (D), Lu Xia ${ }^{2}$ and Huimin Wang ${ }^{1,2,3}$ \\ 1 State Key Laboratory of Hydrology-Water Resources and Hydraulic Engineering, Hohai University, \\ Nanjing 210098, China; hmwang@hhu.edu.cn \\ 2 Institute of Management Science, Hohai University, Nanjing 210098, China; dengmh@hhu.edu.cn (M.D.); \\ bonnie_d@hhu.edu.cn (L.X.) \\ 3 National Engineering Research Center of Water Resources Efficient Utilization and Engineering Safety, \\ Hohai University, Nanjing 210098, China \\ * Correspondence: chenjunfei@hhu.edu.cn; Tel.: +86-025-6851-4605
}

Received: 3 May 2017; Accepted: 20 June 2017; Published: 27 June 2017

\begin{abstract}
A new model for risk assessment of agricultural drought based on information diffusion method and variable fuzzy sets (IDM-VFS) was proposed. In addition, an integrated index system of agricultural drought risk was established. In the proposed model, IDM was employed to calculate the agricultural drought risk level classification standards, and then the VFS was adopted to assess the dangerousness, sensitivity, vulnerability, and comprehensive risk of agricultural droughts. In the present study, Nanpan River Basin was employed to assess the agricultural drought risk with the proposed model. The results showed that KaiYuan, ShiZong, QiuBei, and ZhanYi have higher dangerousness, due to water shortage. GuangNan have higher sensitivity and vulnerability because of lower drought resistance level and higher crop planting proportion. The comprehensive agricultural drought risk shows apparent regional characteristics: the central, western and northwestern counties have lower risk than the eastern counties. Moreover, most areas of the Nanpan River Basin are of moderate agricultural drought risk grade. The results are consistent with the actual situation of Nanpan River Basin and verify the model's effectiveness. The study can provide a scientific reference in drought risk management for local governmental agencies.
\end{abstract}

Keywords: agricultural drought risk assessment; integrated index system; information diffusion method (IDM); variable fuzzy sets (VFS); Nanpan River Basin

\section{Introduction}

Drought originates from a deficiency of precipitation over an extended period of time that results in water shortage for some activity, or some group [1]. It is commonly classified into four typologies: meteorological, agricultural, hydrological, and socio-economic. In recent decades, droughts have occurred more frequently and imposed adverse impacts on natural and human systems [2,3]. China is one of the countries that is most prone to drought disaster [4]. For example, from 2009 to 2011, severe droughts swept China from north to south and from east to west, which caused huge economic and societal losses [5-9]. Drought has become an important factor affecting China's agricultural and sustainable development. The Nanpan River Basin (NRB), located in the southeast of Yunnan-Guizhou Plateau slopes is one of the regions that suffer most from serious and frequent droughts [10]. Therefore, it is important to assess the risk of droughts, which can help to improve the prediction ability of droughts and to reduce the losses caused by droughts.

In order to mitigate losses caused by drought, it is necessary to assess this phenomenon adopting scientific methods. Drought index is a quantitative method that can characterize drought levels through assimilating data from one or several indices into a single numerical value [11]. The WMO 
(World Meteorological Organization) defines drought index as "an index which is related to some of the cumulative effects of a prolonged and abnormal moisture deficiency" [12]. Over the years, several drought indicators have been developed to characterize droughts [13-19]. Most of these studies have focused on a single drought index, e.g., Palmer Drought Severity Index (PDSI) [13], Surface Water Supply Index (SWSI) [14], SPI Standardized Precipitation Index (SPI) [15], and Standardized Precipitation Evapotranspiration Index (SPEI) [16]. However, agricultural drought disaster is a multivariate phenomenon that contains interactive physical linkages including antecedent moisture conditions, soil type, slope, and the intensity of the precipitation event [20]. Hence, several integrated drought indicators that combine different drought variables have proposed by researchers. For example, Safavi et al. [17] developed an integrated index using multiple factors including land use, slope and soil type, precipitation, surface water storage, environment needs and other factors. Rajsekhar et al. [18] constructed a multivariate drought index (MDI) through combing hydrological and meteorological information with precipitation, evapotranspiration, runoff, and soil moisture factors. Waseem et al. [19] developed the antecedent condition-based multivariate drought index (AMDI) that includes climatic water balance, antecedent moisture conditions and other factors.

According to the natural disaster system theory, the occurrence of drought is due to dangerousness of hazard-formative factors, sensitivity of hazard-inducing environment, and vulnerability of hazard-affected bodies. The dangerousness is used to describe the abnormal degree of nature and society. The sensitivity is adopted to depict the responsiveness to nature hazards [21]. The vulnerability is conceptualized as "The conditions determined by physical, social, economic and environmental factors or processes which increase the susceptibility of an individual, a community, assets or systems to the impacts of hazards" [22]. In order to assess agricultural drought risk effectively, this study established the agricultural drought integrated index system with dangerousness indices, sensitivity indices, and vulnerability indices. Therefore, the comprehensive agricultural drought risk is defined as a composite function of dangerousness, sensitivity, and vulnerability based on the natural disaster system theory.

Drought is a fuzzy phenomenon and is difficult to evaluate mainly because of the lack of sufficient data [23]. Therefore, fuzzy and uncertainty theories have been introduced into the drought risk assessment by some researchers, such as fuzzy comprehensive evaluation [24], information diffusion [25], variable fuzzy sets (VFS) [26], and copula [27,28] et al. However, there are some deficiencies in these approaches. For example, the fuzzy comprehensive evaluation cannot well resolve the duplication information caused by related evaluation indices; the establishment of the relative membership function of the variable fuzzy sets depends on physical analysis and expert experience [29]. Taking into consideration these factors, there is a trend that combines the advantages of different of methods to construct a new approach. For example, Li et al. [30] developed a composite model based on improved information diffusion method and variable fuzzy sets to assess the disaster risk. Ouyang et al. [31] put forward a composite method based on information diffusion method and bootstrap to estimate the drought risk levels of drought-prone areas in Anhui province. Deng et al. [32] put forward a composite model based on projection pursuit and information diffusion to assess the risk of drought in the Qujing city of Yunnan province.

The variable fuzzy sets (VFS) can effectively eliminate the border effect on assessment results and make full use of various index data to obtain comprehensive risk evaluation results. The information diffusion method (IDM) can establish the level classification standards of drought risk assessment indices, and help to determine the relative membership function. Hence, in this paper, VFS was combined with IDM as an integrated model to assess the risk of agricultural drought. In the proposed model IDM was employed to calculate the level classification standards of drought risk assessment indices, and then the VFS was adopted to achieve the comprehensive risk evaluation of droughts. In the support of integrated index system and IDM-VFS model, the Nanpan River Basin in Yunnan province was taken as a case study area. The paper is organized as follows. Section 2 depicts the study 
area, followed by the data and methods in Section 3. Section 4 presents the main results and analysis. The discussion and conclusions of the study are given in Section 5 .

\section{Overview of Study Area}

Nanpan River Basin (Figure 1), which is located between $102^{\circ} 14^{\prime} \mathrm{E}-106^{\circ} 7^{\prime} \mathrm{E}$ and $23^{\circ} 12^{\prime} \mathrm{N}-26^{\circ} 27^{\prime} \mathrm{N}$, originates from the east side of Maxiong mountain. The river's total length is $651 \mathrm{~km}$, and its drainage area is $43,311 \mathrm{~km}^{2}$ in Yunnan province. The river basin is significantly dominated by subtropical monsoon climate and dry wet seasonal change. The annual mean temperature ranges from $13^{\circ}$ to $20^{\circ}$. The mean annual precipitation is $921.1 \mathrm{~mm}$. The precipitation mainly occurs from May to October, which account for $86.7 \%$ of annual precipitation, and its uneven distributed making the river basin prone to drought. The spatiotemporal distribution of runoff is similar to precipitation, with annual average natural runoff 1.08 billion $\mathrm{m}^{3}$. In recent years, localized drought disasters have occurred frequently and caused huge losses. Thus, drought has become one of the most important factors that restrict the development of Nanpan River Basin.

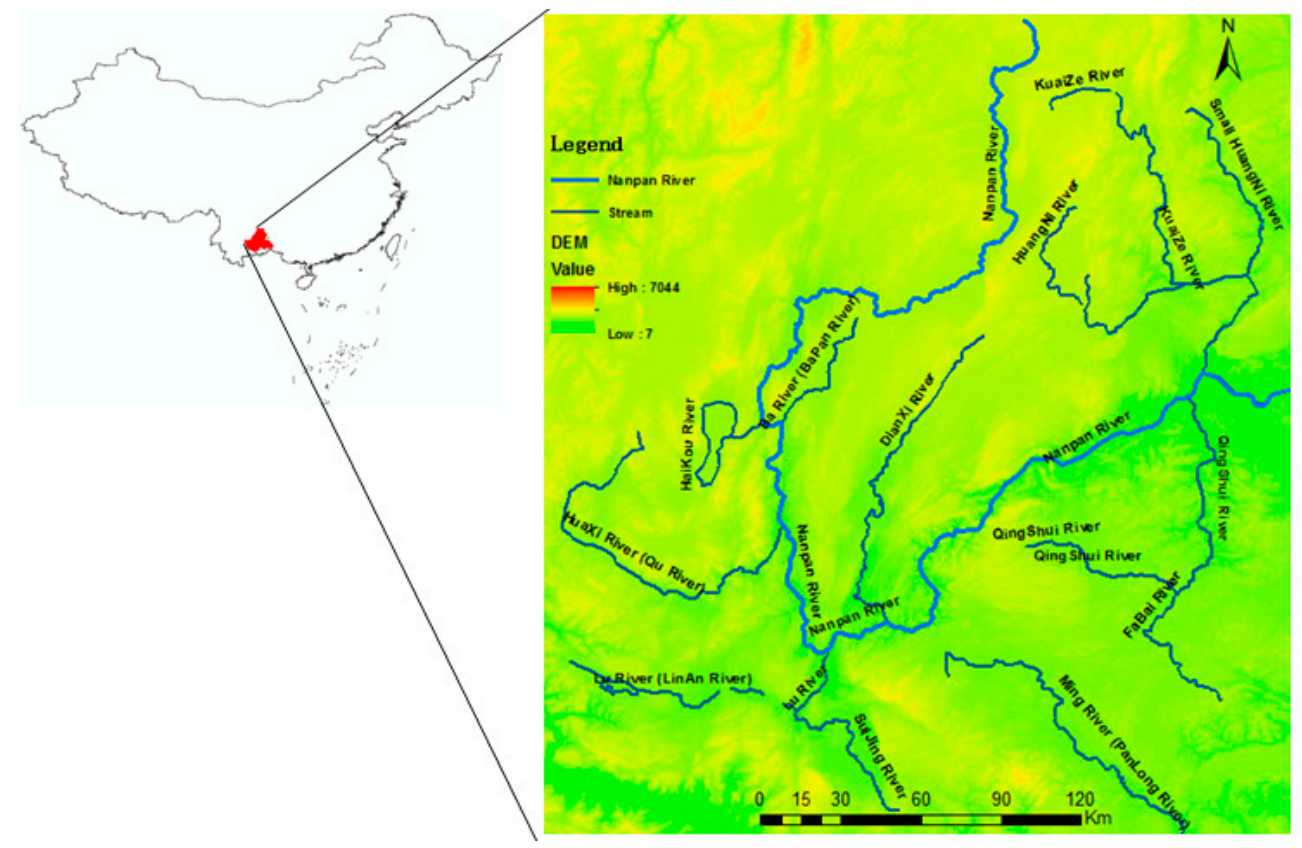

Figure 1. Geographic location of Nanpan River Basin in Yunnan Province, China.

\section{Data and Methods}

\subsection{Data Sources}

The data were collected from Yunnan Statistical Yearbook, Kunming Statistical Yearbook, Qujing Statistical Yearbook, YuXi Statistical Yearbook, Yearbook of HongHe Prefecture, The Almanac of WenShan, Yunnan Water Conservancy Statistics Yearbook, Yunnan Water Resource Bulletin, Yunnan Drought Planning Draft, and Yunnan Drought Briefing. Statistics were provided by the Yunnan Flood Control and Drought Relief Headquarter, and the Yunnan Bureau of Hydrology and Water Resources.

\subsection{Information Diffusion Method (IDM)}

Information diffusion method (IDM) can transform a data sample point into a fuzzy set. The principle of information diffusion is an affirmation: when a knowledge sample is given, it can be adopted to calculate a relationship. The sample is called "non-diffusion estimation". If and only if the sample is incomplete, can the method make the diffusion estimation closer to the real relationship 
than the non-diffusion estimation [33]. In drought risk assessment, the method can establish the level classification standards of drought assessment risk indices to improve the evaluation accuracy. In this paper IDM was employed to calculate the exceeding probability of every index, then based on the national drought planning and drought data, the level classification standards of drought risk assessment indices were established. There are many types of information diffusion methods, e.g., double exponential jump diffusion, logarithmic diffusion, and the normal information diffusion method. Huang and Wang [34] demonstrated that the normal IDM is better than the logarithmic and exponential diffusion method under the small sample size condition. Therefore, in this paper the normal IDM is adopted. The definition of information diffusion can be shown as follows:

Definition 1. Suppose $X=\left\{x_{1}, x_{2}, \cdots, x_{n}\right\}$ is a random sample set, $V$ is the universal field, and the information diffusion method is a mapping $\mu: X \times V \rightarrow[0,1]$ that satisfies the following three conditions [35]:

(1) $\forall x \in X$, let $v^{*}$ be the observed value of $x$, then $\mu\left(x, v^{*}\right)=\max _{v \in V} \mu(x, v)$.

(2) $\forall x \in X, \forall v^{\prime}, v^{\prime \prime} \in V$, if $\left\|v^{\prime}-x\right\| \leq\left\|v^{\prime \prime}-x\right\|$, then $\mu\left(x, v^{\prime}\right) \geq \mu\left(x, v^{\prime \prime}\right)$.

(3) $\forall x \in X, \int_{V} \mu(x, v) d v=1$. If $V$ is discrete, then $\sum_{V} \mu(x, v) d v=1$.

The assessment model based on the information diffusion is shown as follows:

Let the index system for drought risk assessment be $X=\left\{x_{1}, x_{2}, \cdots, x_{n}\right\}, x_{i}(i=1,2, \cdots, n)$ is the observed value, the level domain for the drought risk is $U=\left\{u_{1}, u_{2}, \cdots, u_{m}\right\}, u_{j}(j=1,2, \cdots, m)$ is a value in $U$. According to the national drought planning of China, the drought risk level is divided into lowest risk, lower risk, moderate risk, higher risk, and highest risk, respectively. The information carried by $x_{i}$ can be diffused into $u_{j}$ according to Equation (1).

$$
f_{i}\left(u_{j}\right)=\frac{1}{h \sqrt{2 \pi}} \exp \left[-\frac{\left(x_{i}-u_{j}\right)}{2 h^{2}}\right] \cdots i=1,2, \cdots, n, j=1,2, \cdots, m
$$

Here, $h$ is the diffusion coefficient, can be calculated as follows:

$$
h=\left\{\begin{array}{l}
0.8146(b-a), n=5 \\
0.5690(b-a), n=6 \\
0.4560(b-a), n=7 \\
0.3860(b-a), n=8 \\
0.3362(b-a), n=9 \\
0.2986(b-a), n=10 \\
0.6851(b-a) /(n-1), n \geq 11
\end{array}\right.
$$

where $a=\min _{1 \leq i \leq n}\left\{x_{i}\right\} ; b=\max _{1 \leq i \leq n}\left\{x_{i}\right\}$.

Suppose:

$$
C_{i}=\sum_{j=1}^{m} f_{i}\left(u_{j}\right)
$$

Then, the normalized diffusion function $g_{i}\left(u_{j}\right)$ can be obtained through Equation (4):

$$
g_{i}\left(u_{j}\right)=\frac{f_{i}\left(u_{j}\right)}{C_{i}}
$$

Furthermore, let $q\left(u_{j}\right)=\sum_{i=1}^{n} g_{i}\left(u_{j}\right)$ and $Q=\sum_{j=1}^{m} q\left(u_{j}\right)$, then the probability of samples falls in $u_{j}$ can be represented as follows:

$$
p\left(u_{i}\right)=q\left(u_{J}\right) / Q
$$

The exceeding probability of $u_{j}$ can be obtained through Equation (6). 


$$
P\left(u_{j}\right)=\sum_{k=j}^{m} p\left(u_{k}\right)
$$

Finally, according to drought grade probability classification standard, the level classification standards of drought risk assessment indices can be obtained.

\subsection{Entropy Combination Weighted Method}

The integrated index system of drought risk assessment includes a lot of indices. Each index plays a different role in the integrated system. The index weight reflects the relative importance of each index in the integrated index system. The entropy weight method is an objective method that determines the importance of index based on the information carried by the given data. The more concentrated information that one index provides, the less important the index is. The less concentrated information that one index provides, the more important the index is. The ANP (Analytic Network Process) is a subjective method to determine the weight of indices based on experts' experience [36]. The Super Decisions software can be adopted to determine the ANP weight of an index. Those two methods have their own advantages and disadvantages. Therefore, in this paper, we use a combined method to improve the reliability as follows:

$$
\omega=\alpha \omega_{1}+(1-\alpha) \omega_{2}
$$

where $\omega$ is the combined weight, $\omega_{1}$ is the subjective weight calculated by ANP, $\omega_{2}$ is the objective weight calculated by entropy weight method, $\alpha(0<\alpha<1)$ is the coefficient, in this paper we set $\alpha=0.5$. Then the combined weight vector $\omega$ can be calculated as follows:

$$
\omega=\left(\omega_{1}, \omega_{2}, \cdots, \omega_{m}\right)
$$

where $m$ is the number of sample indicators.

\subsection{Variable Fuzzy Set Theory (VFS)}

Chen proposed the Variable fuzzy sets (VFS) based on engineering fuzzy sets and the relative membership degrees [37]. It extends the static fuzzy set proposed by Zadeh [38] and establishes the dynamic variable fuzzy sets theory. The model can deal well with the variable fuzzy phenomena, such as flood, drought, and so on. Therefore, in this paper after the calculations of the level classification standards of drought risk assessment indices and the weight of each index, the VFS was adopted to obtain the comprehensive risk values. The VFS model is shown as follows:

Assume $A$ is a fuzzy concept in the domain of $U(u \in U), \underset{\sim}{A}$ and $\underset{\sim}{A^{c}}$ are the attract ability of $U$ and the repellency of $U$, respectively. The relative membership degree (RMD) of $\underset{\sim}{A}(\forall u \in U)$ is $\mu_{A}(u)$, which ranges from 0 to 1 . The RMD of $\underset{\sim}{A^{c}}(\forall u \in U)$ is $\mu_{A^{c}}(u)$, which ranges from 1 to 0 . RMD satisfies $\mu_{\sim}(u)+\mu_{\sim}{ }_{\sim}^{c}(u)=1$. The relationship between $\mu_{\sim}(u) \underset{\sim}{\sim} \underset{\sim}{\text { and }} \mu_{A^{c}}(u)$ is shown in Figure 2.

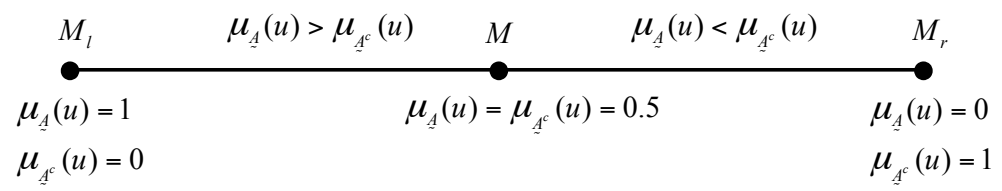

Figure 2. The relation of the relative membership degree function $\mu_{A}(u)$ and $\mu_{A^{c}}(u)$. 
Let $D_{\mathcal{\sim}}(u)=\mu_{\sim}(u)-\mu_{A^{c}}(u)$, where $D_{\sim}(u)$ is defined as the relative difference degree function of $u$ to $\underset{\sim}{A}$ that satisfy the mapping $D: u \rightarrow \underset{\sim}{D_{A}}(u) \in[-1,1]$. Due to $\mu_{\mathcal{A}}(u)+\mu_{A^{c}}(u)=1$, then

$$
\begin{gathered}
D_{\sim}(u)=2 \mu_{\sim}(u)-1 \\
\mu_{\sim}(u)=\left(1+\underset{\sim}{D_{A}}(u)\right) / 2
\end{gathered}
$$

where $0 \leq \mu_{\sim}(u) \leq 1,0 \leq \underset{\sim}{\mu_{A^{c}}}(u) \leq 1$.

Let $\quad V_{0} \quad=\quad\left\{(u, D) \mid u \in U, D_{\sim}^{D_{A}}(u)=\mu_{\sim}(u)-\mu_{\sim} \sim_{\sim}^{c}(u), D \in[-1,1]\right\}, \quad A_{+}=$ $\left\{u \mid u \in U, 0<D_{\mathcal{\sim}}(u)<1\right\}, A_{-}=\left\{u \mid u \in U,-1<D_{\sim}^{D_{\sim}}(u)<0\right\}$ and $A_{0}=\left\{u \mid u \in U, D_{\sim}(u)=0\right\}$. $A_{+}, A_{-}$and $A_{0}$ are defined as the attracting sets, repelling sets and balance boundary of VFS $V_{0}$, respectively. For any element $u$ in the set $V_{0}$ is defined as VFS.

Suppose $X_{0}=[a, b]$ is attracting sets of VFS $V_{0} . X=[c, d]$ is a certain internal containing $X_{0}\left(X_{0} \subset X\right)$. $[c, a]$ and $[b, d]$ are the repelling sets of VFS. $M$ is a point value which satisfies $D_{\mathcal{\sim}}(u)=1$ in attracting sets $[a, b]$, and $M$ can be determined by actual problem or selected as the midpoint value of interval $[a, b]$ (see Figure 3).

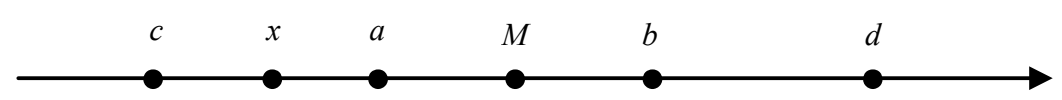

Figure 3. Location relationships among points $x, M$ and internals $[a, b],[c, d]$.

Suppose $x$ is a random point in interval X. Then when $x$ lies in the left side of $M$ :

$$
\left\{\begin{array}{l}
D_{\sim}^{D_{A}}(u)=\left(\frac{x-a}{M-a}\right)^{\beta} ; x \in[a, M] \\
\underset{\sim}{D_{A}}(u)=-\left(\frac{x-a}{c-a}\right)^{\beta} ; x \in[c, a]
\end{array}\right.
$$

When $x$ lies in the right side of $M$ :

$$
\left\{\begin{array}{l}
D_{\sim}(u)=\left(\frac{x-b}{M-b}\right)^{\beta} ; x \in[M, b] \\
D_{\sim}(u)=-\left(\frac{x-b}{d-b}\right)^{\beta} ; x \in[b, d]
\end{array}\right.
$$

In which $\beta \geq 0$, generally, setting $\beta=1$.

Suppose $X=\left\{x_{1}, x_{2}, \cdots, x_{n}\right\}$ is the sample set of drought risk evaluation. The index eigenvalue of the sample $j$ can be expressed as $x_{j}=\left(x_{1 j}, x_{2 j}, \cdots, x_{m j}\right)$ where $m$ is the number of sample indices. Then the sample set can be express as $X=\left(x_{i j}\right)_{m \times n^{\prime}}$ where $i=1,2, \cdots, m, j=1,2, \cdots, n$. $h$ is the total grade number. Then the relative membership degree matrix $U_{h}$ and the integrated relative membership degree ${ }_{i} u_{h}^{\prime}$ can be obtained as follows:

$$
\begin{gathered}
{\left[U_{h}\right]=\left(\mu_{\sim}(u)\right)_{i h}{ }^{\prime} i=1,2, \cdots, m, h=1,2, \cdots, c} \\
{ }_{i} u_{h}^{\prime}=\left(1+\left[\frac{\sum_{i=1}^{m}\left[\omega_{i}\left(1-\mu_{\sim}(u)_{i h}\right)\right]^{p}}{\sum_{i=1}^{m}\left(\omega_{i} \mu_{A}(u)_{i h}\right)^{p}}\right]^{\frac{\alpha}{p}}, i=1,2, \cdots, m, h=1,2, \cdots, c\right.
\end{gathered}
$$


where, $\omega_{i}$ is the weight of index that can be calculated by Equation (8); $\alpha$ is the optimal rule parameter, $\alpha=1$ is the least single method and $\alpha=2$ is the least square method; $p$ is the distance parameter, $p=1$ is Hamming distance and $p=2$ is Euclidean distance. ${ }_{i} u_{h}^{\prime}$ is the non-normalized relative membership degree; Let the matrix of ${ }_{i} u_{h}^{\prime}$ is $U^{\prime}=\left({ }_{i} u_{h}^{\prime}\right)$. Then the normalized relative membership degree ${ }_{i} u_{h}$ can be obtained through Equation (15), and the matrix of ${ }_{i} u_{h}$ is $U=\left({ }_{i} u_{h}\right)$.

$$
{ }_{i} u_{h}={ }_{i} u_{h}^{\prime} / \sum_{h=1}^{c}{ }_{i} u_{h}^{\prime}
$$

Finally, by adopting ranking feature value method, drought risk grade values of samples can be obtained through Equation (16).

$$
H=(1,2, \cdots, c) \cdot U
$$

\subsection{Assessment Steps Basedon IDM-VFS Model}

(1) The combination weight of each drought index can be calculated by Equations (7) and (8).

(2) Based on the IDM model, the level classification standards of drought risk assessment indices can be calculated.

(3) According to the matrix of drought risk indices level classification standard, the interval matrix $I_{a b}=\left([a, b]_{i h}\right)$, the bound matrix $I_{c d}=\left([c, d]_{i h}\right)$, and the point value matrix $M=\left(M_{i h}\right)$ of index $i$ and grade $h$ can be obtained, where $i=1,2, \cdots, m, h=1,2, \cdots, c$. Then based on Equations (10)-(15), the relative membership degree matrix $U_{h}$ and the integrated relative membership degree ${ }_{i} u_{h}$ can be obtained. Finally, based on the equation of (16), the grade characteristic values $(H)$ of the samples can be calculated.

(4) The grade of drought risk can be obtained through Equation (17)

$$
R=W \times H
$$

where, $R$ is the comprehensive risk of each region; $W$ is the combinations weight.

\section{Results and Analysis}

\subsection{Agricultural Drought Index System}

The reasonable indices of agricultural drought risk assessment should be able to accurately describe the drought extent, and contain a clearly physical mechanism such as precipitation, evapotranspiration, soil, and so on. According to the natural disaster system theory and the actual situation of Nanpan River Basin, an integrated risk assessment indicator system of agricultural drought was established (see Figure 4). The entire index system is divided into three subsystems: dangerousness, sensitivity, and vulnerability.

The dangerousness indices describer the abnormal degree of nature and society. Among them the extreme precipitation and temperature are the main inducement of droughts. Generally, the higher the dangerousness the easier the drought disaster appears. That is, precipitation anomaly percentage $\left(I_{11}: \%\right)$, homogenization of precipitation and temperature $\left(I_{12}\right)$, soil moisture from November to April $\left(I_{13}: \%\right)$, per capita water resources $\left(I_{14}: \mathrm{m}^{3} /\right.$ person) and reservoir water storage capacity $\left(I_{15}: \%\right)$ are chosen to describe the dangerousness subsystem. Among them, soil moisture from November to April is determined by rate of water content of soil weight and the relative moisture of soil; reservoir water storage capacity is equal to reservoir water storage capacity at the end of year divided by average water storage capacity.

The sensitivity indices mainly describe the responsiveness to drought. The sensitivity of hazard-inducing environment includes: climate, soil, economic development level, basic irrigation facilities and other natural, social, economic and ecosystems. The greater the sensitivity, the larger 
the losses of drought. The rural per capita net income ( $I_{21}$ : Yuan), agricultural irrigation water consumption per acre $\left(I_{22}: \mathrm{m}^{3} / \mathrm{mu}\right)$, water quantity per acre $\left(I_{23}: \mathrm{m}^{3} / \mathrm{mu}\right)$, rate of irrigated cultivated land $\left(I_{24}: \%\right)$, water-saving irrigation proportion $\left(I_{25}: \%\right)$, security area ratio $\left(I_{26}: \%\right)$, electromechanical drainage and irrigation area ratio $\left(I_{27}: \%\right)$, drought relief investment level $\left(I_{28}: \%\right)$ and emergency response ability $\left(I_{29}\right)$ are chosen to depict the sensitivity subsystem. Among them, the drought relief investment level refers to the level of actual investment that is needed in order to mitigate the loss caused by drought and emergency response ability refers to the ability of the region to respond to drought. Both factors are determined by experts' experience.

The vulnerability indices reflect the anti-disaster capability. The higher the value vulnerability of hazard-affected bodies, the greater the loss will be. The agricultural population density $\left(I_{31}\right.$ : person $\left./ \mathrm{km}^{2}\right)$, crop planting proportion $\left(I_{32}: \%\right)$, grain output per unit area $\left(I_{33}: \mathrm{kg} / \mathrm{mu}\right)$, agricultural output value density $\left(I_{34}:\right.$ ten thousand $\left./ \mathrm{km}^{2}\right)$, drought rate $\left(I_{34}: \%\right)$ and hazard rate $\left(I_{35}: \%\right)$ are selected to depict the vulnerability subsystem. Among them, the crop planting proportion is equal to crop areas divided by land areas; agricultural output value density is equal to gross agricultural production divided by land areas.

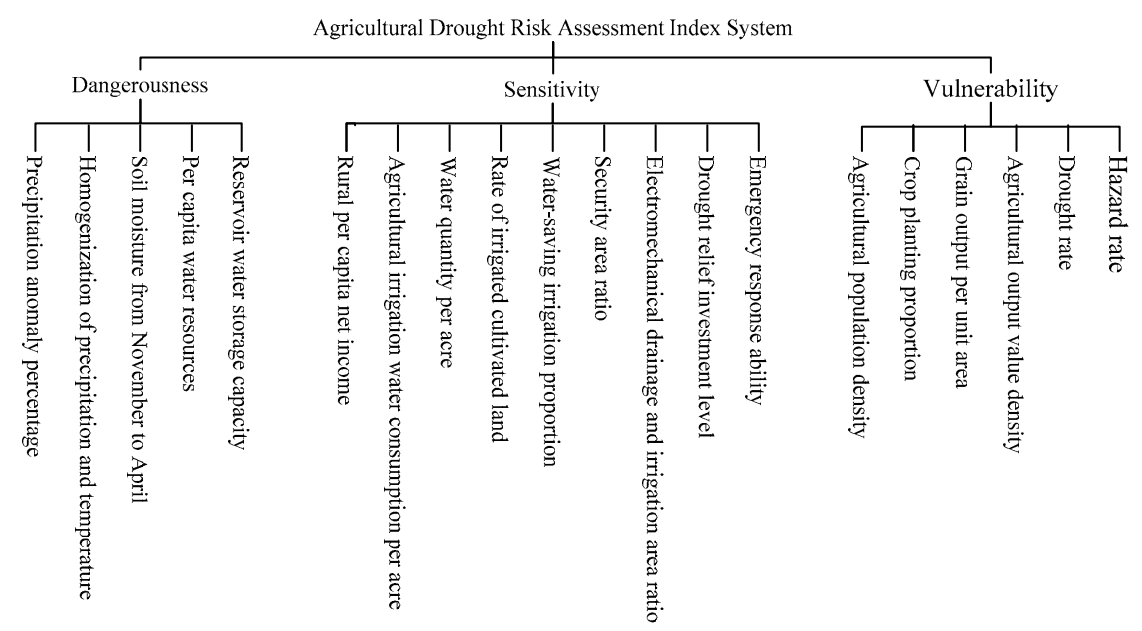

Figure 4. Agricultural drought risk assessment index system.

\subsection{Evaluate Drought Risk Based on IDM-VFS Model}

Based on the agricultural drought risk assessment index system and IDM-VFS model, firstly the ANP was combined with entropy to determine the weight of drought risk indices; then the information diffusion model was adopted to determine the level classification standards of drought risk assessment indices; and then the VFS model was employed to calculate the drought risk values in dangerousness, sensitivity, and vulnerability, respectively. Finally, the comprehensive drought risk grade was obtained and the risk zoning map was drawn. For demonstration purposes, Shilin has been chosen as an example to discuss the risk assessment of drought in detail.

\subsubsection{The Index Values of Shilin from 2000 to 2010}

For better readability, the index values were shown in terms of dangerousness, sensitivity, and vulnerability, respectively (see Tables 1-3). 
Table 1. Index values of dangerousness for drought risk assessment in Shilin.

\begin{tabular}{cccccc}
\hline Year & $\begin{array}{c}\text { Precipitation } \\
\text { Anomaly } \\
\text { Percentage (\%) }\end{array}$ & $\begin{array}{c}\text { Homogenization of } \\
\text { Precipitation and } \\
\text { Temperature }\end{array}$ & $\begin{array}{c}\text { Soil Moisture } \\
\text { from November to } \\
\text { April (\%) }\end{array}$ & $\begin{array}{c}\text { Per Capita Water } \\
\text { Resources } \\
\text { (m } \mathbf{3}^{\mathbf{3}} \text { person) }\end{array}$ & $\begin{array}{c}\text { Reservoir } \\
\text { Water Storage } \\
\text { Capacity (\%) }\end{array}$ \\
\hline 2000 & 6.25 & 1.44 & 58.14 & 1849.19 & -38.07 \\
2001 & 4.47 & 1.39 & 76.86 & 1997.33 & -35.85 \\
2002 & 14.23 & 0.85 & 69.07 & 2232.97 & -13.73 \\
2003 & -2.56 & -1.32 & 51.76 & 1844.74 & -25.11 \\
2004 & -3.95 & 1.49 & 62.40 & 2104.12 & 10.25 \\
2005 & -9.24 & 0.02 & 59.38 & 2034.91 & 26.95 \\
2006 & -5.10 & -0.78 & 52.36 & 1678.53 & 28.76 \\
2007 & 2.44 & 1.34 & 69.07 & 2093.22 & 5.34 \\
2008 & -6.78 & 1.62 & 68.63 & 2139.32 & 38.48 \\
2009 & -34.74 & -3.74 & 35.05 & 1221.31 & -2.25 \\
2010 & -29.03 & -2.32 & 50.29 & 1530.61 & 5.25 \\
\hline
\end{tabular}

Table 2. Index values of sensitivity for drought risk assessment in Shilin.

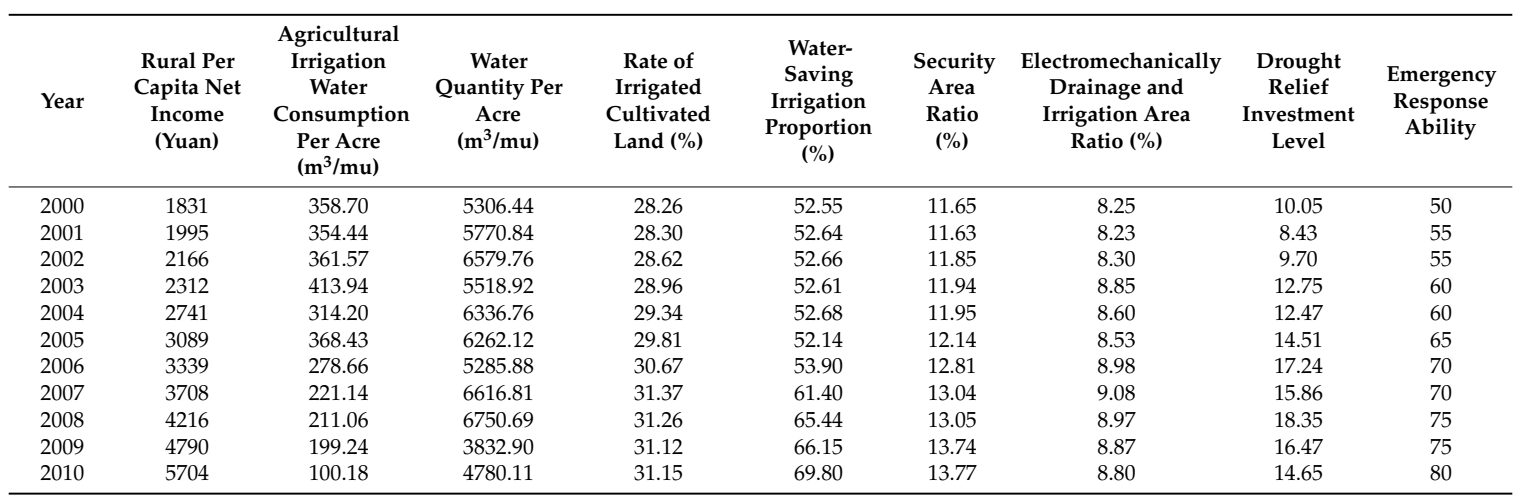

Table 3. Index values of vulnerability for drought risk assessment in Shilin.

\begin{tabular}{ccccccc}
\hline Year & $\begin{array}{c}\text { Agricultural } \\
\text { Population Density } \\
\text { (Person/km } \mathbf{~}^{\text {) }}\end{array}$ & $\begin{array}{c}\text { Crop Planting } \\
\text { Proportion (\%) }\end{array}$ & $\begin{array}{c}\text { Grain Output } \\
\text { Per Unit Area } \\
\mathbf{( k g / m u )}\end{array}$ & $\begin{array}{c}\text { Agricultural Output } \\
\text { Value Density (Ten } \\
\text { Thousand/km } \mathbf{~})\end{array}$ & $\begin{array}{c}\text { Drought } \\
\text { Rate (\%) }\end{array}$ & $\begin{array}{c}\text { Hazard } \\
\text { Rate (\%) }\end{array}$ \\
\hline 2000 & 119.82 & 12.99 & 327.11 & 13.42 & 2.30 & 2.21 \\
2001 & 120.24 & 12.93 & 326.26 & 15.13 & 10.22 & 9.12 \\
2002 & 117.14 & 12.90 & 322.38 & 16.42 & 34.21 & 29.28 \\
2003 & 117.74 & 13.00 & 313.41 & 17.21 & 11.17 & 7.49 \\
2004 & 119.23 & 13.98 & 316.03 & 37.34 & 6.92 & 4.63 \\
2005 & 119.40 & 14.54 & 309.08 & 38.55 & 2.13 & 1.66 \\
2006 & 125.36 & 14.73 & 304.00 & 38.79 & 17.95 & 15.66 \\
2007 & 121.13 & 14.83 & 303.14 & 44.42 & 13.85 & 8.12 \\
2008 & 121.67 & 16.48 & 281.59 & 52.68 & 20.05 & 16.05 \\
2009 & 122.38 & 16.81 & 274.03 & 56.14 & 15.67 & 4.18 \\
2010 & 125.00 & 17.96 & 258.09 & 59.15 & 35.19 & 31.74 \\
\hline
\end{tabular}

4.2.2. Determine the Weight of Agricultural Drought Risk Indices

Index weight was determined by combined entropy weight method and ANP. The weight of agricultural drought risk assessment indices was shown in Table 4. 
Table 4. Weight of agricultural drought risk assessment indices.

\begin{tabular}{|c|c|c|c|}
\hline Index & Weight & Index & Weight \\
\hline Precipitation Anomaly Percentage (\%) & 0.0439 & Security Area Ratio (\%) & 0.0196 \\
\hline $\begin{array}{l}\text { Homogenization of Precipitation } \\
\text { and Temperature }\end{array}$ & 0.0537 & $\begin{array}{l}\text { Electromechanical Drainage and } \\
\text { Irrigation Area Ratio (\%) }\end{array}$ & 0.0552 \\
\hline Soil Moisture from November to April (\%) & 0.0900 & Drought Relief Investment Level (\%) & 0.0157 \\
\hline Per Capita Water Resources ( $\mathrm{m}^{3} /$ person) & 0.0743 & Emergency Response Ability & 0.0652 \\
\hline Reservoir Water Storage Capacity (\%) & 0.0618 & Agricultural Population Density & 0.0248 \\
\hline Rural Per Capita Net Income (yuan) & 0.0803 & Crop planting Proportion (\%) & 0.0230 \\
\hline $\begin{array}{l}\text { Agricultural Irrigation Water Consumption } \\
\text { Per Acre }\left(\mathrm{m}^{3} / \mathrm{mu}\right)\end{array}$ & 0.0534 & Grain Output Per Unit Area (kg/mu) & 0.0594 \\
\hline Water Quantity Per Acre $\left(\mathrm{m}^{3} / \mathrm{mu}\right)$ & 0.0594 & $\begin{array}{l}\text { Agricultural Output Value Density } \\
\left(\text { ten thousand } / \mathrm{km}^{2}\right)\end{array}$ & 0.0703 \\
\hline Rate of Irrigated Cultivated Land (\%) & 0.0302 & Drought Rate (\%) & 0.0399 \\
\hline Water-saving Irrigation Proportion (\%) & 0.0212 & Hazard Rate (\%) & 0.0584 \\
\hline
\end{tabular}

\subsubsection{Calculate the Level Classification Standards of Agricultural Drought Risk Assessment Indices}

The level classification standards of each agricultural drought risk assessment index are determined by IDM. Firstly, the index values were taken as samples of information diffusion, then the exceeding probability of each indicator were calculated; finally, the level classification standards of each drought risk assessment index were obtained (see Table 5).

Table 5. Level classification standards of each agricultural drought risk assessment index.

\begin{tabular}{|c|c|c|c|c|c|}
\hline \multirow[b]{2}{*}{ Index } & \multicolumn{5}{|c|}{ Drought Level Standards } \\
\hline & $\begin{array}{l}\text { First Level } \\
\text { Lowest }\end{array}$ & $\begin{array}{l}\text { Second Level } \\
\text { Lower }\end{array}$ & $\begin{array}{l}\text { Third Level } \\
\text { Moderate }\end{array}$ & $\begin{array}{l}\text { Forth Level } \\
\text { Higher }\end{array}$ & $\begin{array}{l}\text { Fifth Level } \\
\text { Highest }\end{array}$ \\
\hline Precipitation Anomaly Percentage (\%) & $>-9.1$ & $-24.5--9.1$ & $-33.1--24.5$ & $-44.5--33.1$ & $<-44.5$ \\
\hline $\begin{array}{l}\text { Homogenization of Precipitation } \\
\text { and Temperature }\end{array}$ & $>-0.3$ & $-0.7--0.3$ & $-1.3--0.7$ & $-2.6--1.3$ & $<-2.6$ \\
\hline Soil Moisture from November to April (\%) & $>70$ & $56-70$ & $44-56$ & $33-44$ & $<33$ \\
\hline Per Capita Water Resources $\left(\mathrm{m}^{3} /\right.$ person) & $>5180$ & $3680-5180$ & $1680-3680$ & $680-1680$ & $<680$ \\
\hline Reservoir Water Storage Capacity (\%) & $>80$ & $50-80$ & $30-50$ & $-10-30$ & $<-10$ \\
\hline Rural Per Capita Net Income (yuan) & $>5500$ & $4275-5500$ & $2775-4275$ & $1048-2775$ & $<1048$ \\
\hline $\begin{array}{l}\text { Agricultural Irrigation Water } \\
\text { Consumption Per Acre }\left(\mathrm{m}^{3} / \mathrm{mu}\right)\end{array}$ & $<140$ & $140-292$ & $292-594$ & $594-819$ & $>819$ \\
\hline Water Quantity Per Acre $\left(\mathrm{m}^{3} / \mathrm{mu}\right)$ & $>1613$ & $1315-1613$ & $1197-1315$ & $829-1197$ & $<829$ \\
\hline Rate of Irrigated Cultivated Land (\%) & $>63$ & $50-63$ & $34-50$ & $25-34$ & $<25$ \\
\hline Water-saving Irrigation Proportion (\%) & $>46$ & $36-46$ & $27-36$ & $12-27$ & $<12$ \\
\hline Security Area Ratio $(\%)$ & $>31$ & $24-31$ & $24-19$ & $14-19$ & $<14$ \\
\hline $\begin{array}{l}\text { Electromechanical Drainage and Irrigation } \\
\text { Area Ratio }(\%)\end{array}$ & $>28$ & $22-28$ & $14-22$ & $6-14$ & $<6$ \\
\hline Drought Relief Investment Level (\%) & $>17$ & $15-17$ & $13-15$ & $9-13$ & $<9$ \\
\hline Emergency Response Ability & $>90$ & $70-90$ & $40-70$ & $20-40$ & $<20$ \\
\hline Agricultural Population Density & $<50$ & $50-136$ & $136-286$ & $286-378$ & $>378$ \\
\hline Crop Planting Proportion (\%) & $<6$ & $6-18$ & $18-25$ & $25-40$ & $>40$ \\
\hline Grain Output Per Unit Area $(\mathrm{kg} / \mathrm{mu})$ & $>450$ & $350-450$ & $250-350$ & $150-250$ & $<150$ \\
\hline $\begin{array}{l}\text { Agricultural Output Value Density } \\
\text { (ten thousand } / \mathrm{km}^{2} \text { ) }\end{array}$ & $>56$ & $36-56$ & $15-36$ & $5-15$ & $<5$ \\
\hline Drought Rate $(\%)$ & $<7$ & $7-12$ & $12-24$ & $24-31$ & $>31$ \\
\hline Hazard Rate $(\%)$ & $<5$ & $5-11$ & $11-20$ & $20-25$ & $>25$ \\
\hline
\end{tabular}




\subsubsection{Calculate Agricultural Drought Risk in Terms of Three Subsystems}

According to Table 5, the interval matrix, bound matrix and point value matrix were established, and then, based on Equations (10)-(16), the relative membership degree matrix and integrated membership degree were obtained, and finally the drought risk was calculated in terms of dangerousness, sensitivity, and vulnerability, respectively. The risk values of agricultural drought in Shilin from 2000 to 2010 were shown in Table 6.

Table 6. Agricultural drought risk values of Shilin from 2000 to 2010.

\begin{tabular}{cccc}
\hline Year & Dangerousness & Sensitivity & Vulnerability \\
\hline 2000 & 1.35 & 2.87 & 2.98 \\
2001 & 1.50 & 3.21 & 3.05 \\
2002 & 1.28 & 3.98 & 3.09 \\
2003 & 2.07 & 3.19 & 3.01 \\
2004 & 1.65 & 3.89 & 2.93 \\
2005 & 2.48 & 3.86 & 3.08 \\
2006 & 2.35 & 3.71 & 3.06 \\
2007 & 1.54 & 3.46 & 3.04 \\
2008 & 1.72 & 3.35 & 3.08 \\
2009 & 4.22 & 3.17 & 3.00 \\
2010 & 3.88 & 2.96 & 3.10 \\
Average & 2.19 & 3.42 & 3.04 \\
\hline
\end{tabular}

From Table 6, the dangerousness of 2009 is higher than other years. The vulnerability of 2010 is more serious than other years. In 2009, the precipitation was less than the normal level, the temperature was higher, and the water source in soil moisture was lower, resulting in the drought relief being difficult. The average risk value of dangerousness is 2.19 , the average risk value of sensitivity is 3.42 , and the average risk value of vulnerability is 3.04 .

Adopting the same methods and procedures, we can obtain the average agricultural drought risk values of the other 24 counties in terms of dangerousness, sensitivity, and vulnerability, respectively (see Table 7).

Table 7. Agricultural drought dangerousness, sensitivity, and vulnerability, respectively.

\begin{tabular}{cccc}
\hline County & Dangerousness & Sensitivity & Vulnerability \\
\hline YiLiang & 2.02 & 2.59 & 2.13 \\
ShiLin & 2.19 & 3.42 & 3.04 \\
QiLin & 1.75 & 2.10 & 2.02 \\
MaLong & 1.69 & 2.98 & 2.97 \\
LuLiang & 1.73 & 2.72 & 2.46 \\
ShiZong & 2.79 & 2.60 & 3.10 \\
LuoPing & 1.90 & 3.32 & 2.67 \\
FuYuan & 1.99 & 3.69 & 2.95 \\
ZhanYi & 2.53 & 2.99 & 2.97 \\
HongTa & 1.75 & 2.45 & 1.44 \\
JiangChuan & 1.66 & 2.46 & 1.46 \\
Chengjiang & 1.79 & 2.84 & 1.54 \\
TongHai & 1.66 & 2.64 & 2.02 \\
HuaNing & 1.67 & 2.66 & 1.83 \\
ErShan & 2.13 & 2.80 & 2.75 \\
GeJiu & 1.68 & 3.38 & 2.16 \\
KaiYuan & 2.93 & 3.28 & 2.97 \\
MengZi & 1.57 & 3.80 & 2.33 \\
JianShui & 1.51 & 3.71 & 2.95 \\
ShiPing & 1.64 & 3.49 & 3.18 \\
MiLe & 1.88 & 3.91 & 3.23 \\
LuXi & 1.64 & 3.68 & 2.87 \\
YanShan & 1.72 & 3.62 & 2.70 \\
QiuBei & 2.76 & 3.72 & 2.82 \\
GuangNan & 1.86 & 4.12 & 3.12 \\
\hline
\end{tabular}


The dangerousness of droughts shows obvious regional characteristics in 25 counties in Nanpan River Basin. The dangerousness of KaiYuan, ShiZong, QiuBei, and ZhanYi are higher, while JianShui, LuXi, ShiPing, JiangChuan, TongHai are lower from 2000 to 2010. The major influence factors of dangerousness are meteorological conditions and water resources. The Precipitation decreased from east to west gradually, and the west regions are relatively short of water from 2000 to 2010.

The sensitivity of QiLin and HongTa are lower, while GuangNan, MiLe, QiuBei, LuXi, and ShiPing are higher. The drought sensitivity mainly depends on natural resources and drought resistance level. Water resource distribution in the Nanpan River Basin is uneven. In recent years, the local government has increased investment in drought resistant. However, the drought resistant investments in GuangNan, and QiuBei are lower, resulting in higher sensitivity.

HongTa and JiangChuan are located in the lowest drought vulnerability area, while MaLong and GuangNan are in the highest. The vulnerability of drought is the reflection of industrial structure and crop planting conditions. HongTa, JiangChuang, and TongHai are lower crop planting proportion and agricultural population density so they belong to the lower drought vulnerability counties. The crop planting proportion in MaLong and GuangNan is more than $15 \%$ and the agricultural population density is higher, leading to the highest drought vulnerability.

The comparisons in terms of drought dangerousness, sensitivity, and vulnerability, respectively in Nanpan River Basin was shown in Figure 5.

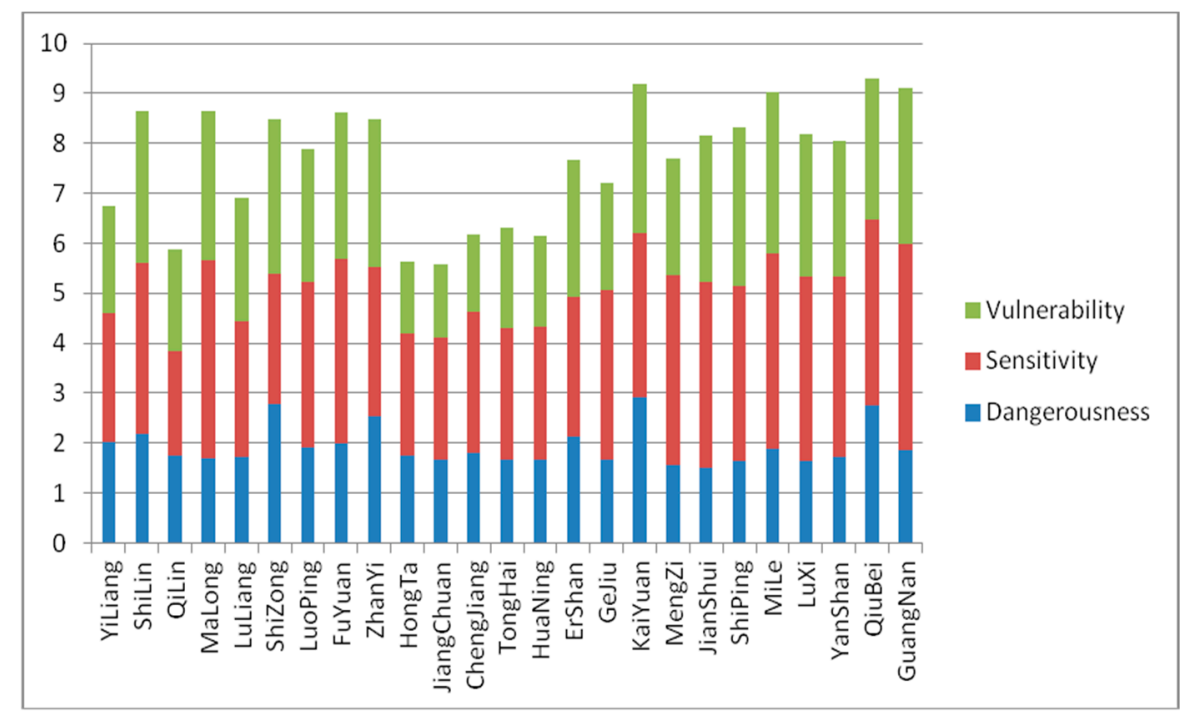

Figure 5. Comparison of drought dangerousness, sensitivity, and vulnerability, respectively in Nanpan river basin.

\subsubsection{Calculate the Comprehensive Risk Assessment of Agricultural Droughts}

The comprehensive agricultural drought risk grades in Nanpan River Basin were shown in Table 8.

Based on the assessment results, the comprehensive risk zoning map in Nanpan River Basin was drawn.

From Figure 6, it can be see that the comprehensive risk drought in Nanpan River Basin has regional characteristics. The comprehensive drought risk in Mengzi, Mile, Yanshan, Qiubei, Guangnan is higer, while that in Yiliang, Qilin, Luliang, Luoping, Hongta, Jiangchuang, Chengjiang, Tonghaiis lower. The risk level in the central, western and northwestern areas lower than the eastern area in the Nanpan River Basin. Moreover, most areas of Nanpan River Basin experience moderate drought. 
Table 8. Comprehensive agricultural drought risk in Nanpan river basin.

\begin{tabular}{cccc}
\hline Country & Risk Level & Country & Risk Level \\
\hline YiLiang & 2 & HuaNing & 3 \\
ShiLin & 3 & ErShan & 3 \\
QiLin & 2 & GeJiu & 3 \\
MaLong & 3 & KaiYuan & 3 \\
LuLiang & 2 & MengZi & 4 \\
ShiZong & 3 & JianShui & 3 \\
LuoPing & 2 & ShiPing & 3 \\
FuYuan & 3 & MiLe & 4 \\
ZhanYi & 3 & LuXi & 3 \\
HongTa & 2 & YanShan & 4 \\
JiangChuan & 2 & QiuBei & 4 \\
ChengJiang & 2 & GuangNan & 4 \\
TongHai & 2 & & \\
\hline
\end{tabular}

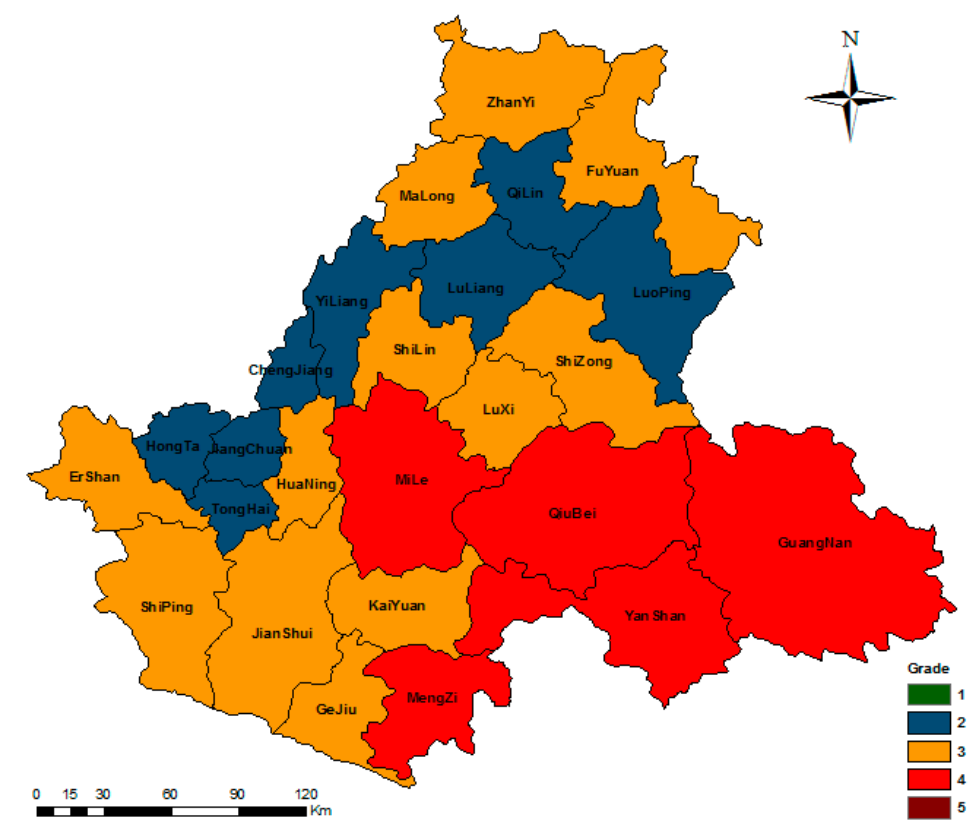

Figure 6. Distribution of comprehensive drought risk in the Nanpan River Basin.

\section{Discussion and Conclusions}

With global climate change, droughts are occurring more frequently in China, and drought risk assessment is important for drought management. However, drought is a fuzzy phenomenon and there is a lack of sufficient data. It is difficult to depict it accurately through traditional statistics, especially in small sample problems. Therefore, some fuzzy and uncertainty theories have been developed to assess the risk of drought. The variable fuzzy sets (VFS) can make full use of various index data to obtain comprehensive risk evaluation results. The information diffusion method (IDM) can transform a sample observed value into a fuzzy set and is capable of dealing with small sample problems. Meanwhile, IDM can extract useful information and establish the level classification standards of agricultural drought risk assessment indices, which is helpful to determine the relative membership function of VFS. Therefore, in this research, a new model for agricultural drought risk assessment based on information diffusion and variable fuzzy sets was proposed. In the IDM-VFS model, VFS was adopted to assess the dangerousness, sensitivity, and vulnerability of agricultural drought and the comprehensive agricultural drought risk of the Nanpan River Basin. 
According to the natural disaster system theory and actual situation of Nanpan River Basin, an integrated agricultural drought risk index system with drought dangerousness indices, drought sensitivity indices, and drought vulnerability indices was established. In the support of integrated index system and IDM-VFS model, the Nanpan River Basin in Yunnan province was taken as a case study area. There are many studies of drought around the world, but very few in the Nanpan River Basin. Previous studies in the Nanpan River Basin have focused on the spatial and temporal distribution of drought events and the links with some climate indices. Considering the integrated impact of dangerousness of hazard-formative factors, sensitivity of hazard-inducing environment, and vulnerability of hazard-affected bodies, to establish an integrated index system of agricultural drought risk in Nanpan River Basinet is helpful to support drought risk management and develop effective mitigation strategies in this region. The results showed that KaiYuan, ShiZong, QiuBei, and ZhanYi have higher dangerousness, due to water shortage. Moreover, the sensitivity and vulnerability in GuangNan are higher than other regions because of lower drought resistance level and higher crop planting proportion. The comprehensive drought risk shows apparent regional characteristics, the central, western and northwestern counties have lower risk than the eastern counties. In addition, most areas of the Nanpan River Basin are located in a moderate drought risk region. The results are consistent with the actual situation of the Nanpan River Basin and can provide reference and decision-making for the emergency management department. However, due to the complexity of risk assessment of droughts, the formation mechanism, and risk management of regional drought need to be studied further.

Acknowledgments: This research was supported by the State Key Program of National Nature Science Foundation of China (Grant No. 71433003), the Major Program of National Social Science Foundation of China (Grant No. 12\&ZD214), 2014 Jiangsu Province Qing Lan Project of China, the Fundamental Research Funds for the Central Universities (Grant No. 2016B46414) and 2016 Jiangsu Province Graduate Student Innovation Project of China.

Author Contributions: Junfei Chen had the original idea for the study; Lu Xia and Menghua Deng were responsible for data collection; Menghua Deng and Lu Xia analyzed the data and wrote the paper; Junfei Chen and Huimin Wang reviewed the paper.

Conflicts of Interest: The authors declare no competing financial interests.

\section{References}

1. Drought Risk Reduction Framework and Practices: Contributing to the Implementation of the Hyogo Framework for Action. Available online: https://www.unisdr.org/we/inform/publications/11541 (accessed on 3 May 2017).

2. Sohrabi, M.M.; Ryu, J.H.; Abatzoglou, J.; Tracy, J. Development of Soil Moisture Drought Index to Characterize Droughts. Available online: https://doi.org/10.1061/(ASCE)HE.1943-5584.0001213\#sthash. 2tNBuout.dpuf (accessed on 3 May 2017).

3. Touma, D.; Ashfaq, M.; Nayak, M.A.; Kao, S.C.; Diffenbaugh, N.S. A multi-model and multi-index evaluation of drought characteristics in the 21st century. J. Hydrol. 2015, 526, 196-207. [CrossRef]

4. Park, S.; Im, J.; Jang, E.; Rhee, J. Drought assessment and monitoring through blending of multi-sensor indices using machine learning approaches for different climate regions. Agric. For. Meteorol. 2016, 216, 157-169. [CrossRef]

5. Wang, Q.F.; Wu, J.J.; Lei, T.J.; He, B.; Wu, Z.T.; Liu, M.; Mo, X.Y.; Geng, G.P.; Li, X.H.; Zhou, H.K.; et al. Temporal-spatial characteristics of severe drought events and their impact on agriculture on a global scale. Quatern. Int. 2014, 349, 10-21.

6. Lu, E.; Cai, W.Y.; Jiang, Z.H.; Zhang, Q.; Zhang, C.J.; Higgins, R.W.; Halpert, M.S. The day-to-day monitoring of the 2011 severe drought in China. Clim. Dyn. 2013, 43, 1-9. [CrossRef]

7. Zhang, M.J.; He, J.Y.; Wang, B.L.; Wang, S.J.; Li, S.S.; Liu, W.L.; Ma, X.N. Extreme drought changes in Southwest China from 1960 to 2009. J. Geogr. Sci. 2013, 23, 3-16. [CrossRef]

8. Hao, C.; Zhang, J.H.; Yao, F.M. Multivariate drought frequency estimation using copula method in Southwest China. Theor. Appl. Climatol. 2017, 127, 977-991. [CrossRef] 
9. Huang, Y.H.; Chen, X.; Yang, H.J.; Wang, J.H.; Jiang, D.; Zhao, C.P. Temporal and spatial variability of droughts in southwest China. Sustainability 2015, 7, 13597-13609. [CrossRef]

10. Jia, C.Q.; Dong, Y.J.; Peng, J.T. Spatial-temporal laws of droughts and floods cross Nanpan River Basin. J. Arid. Land. Resour. Environ. 2014, 28, 104-108. (In Chinese)

11. Zargar, A.; Sadiq, R.; Naser, B.; Khan, F.I. A review of drought indices. Environ. Rev. 2011, 19, 333-349. [CrossRef]

12. World Meteorological Organization. Meteorological Vocabulary (Wmo/omm/bmo); Secretariat of World Meteorological Organizat: Geneva, Switzerland, 1992; p. 784.

13. Palmer, W.C. Meteorological Drought; Weather Bureau Research Paper No. 45; US Department of Commerce: Washington, DC, USA, 1965; p. 58.

14. Shafer, B.; Dezman, L. Development of a Surface Water Supply Index (SWSI) to assess the severity of drought conditions in snowpack runoff areas. In Proceedings of the 50th Annual Western Snow Conference, Colorado State University, Fort Collins, CO, USA, 19-23 April 1982; pp. 164-175.

15. McKee, T.B.; Doesken, N.J.; Kleist, J. The relationship of drought frequency and duration to time scales. In Proceedings of the 8th Conference on Applied Climatology, Anaheim, CA, USA, 17-22 January 1993; pp. 179-184.

16. Vicente-Serrano, S.M.; Beguería, S.; López-Moreno, J.I. A multiscalar drought index sensitive to global warming: The standardized precipitation evapotranspiration index. J. Clim. 2010, 23, 1696-1718. [CrossRef]

17. Safavi, H.R.; Esfahani, M.K.; Zamani, A.R. Integrated index for assessment of vulnerability to drought, case study: Zayandehrood River Basin, Iran. Water. Resour. Manag. 2014, 28, 1671-1688. [CrossRef]

18. Rajsekhar, D.P.; Singh, V.K.; Mishra, A. Multivariate drought index: An information theory based approach for integrated drought assessment. J. Hydrol. 2015, 526, 164-182. [CrossRef]

19. Waseem, M.; Ajmal, M.; Lee, J.H.; Kim, T.W. Multivariate drought assessment considering the antecedent drought conditions. Water. Resour. Manag. 2016, 30, 4221-4231. [CrossRef]

20. Heim, R.R. A review of twentieth-century drought indices used in the United States. Bull. Am. Meteorol. Soc. 2002, 83, 1149-1165.

21. IPCC. Climate Change: Impacts, Adaptation and Vulnerability; Contribution of Working Group II to the Fourth Assessment Report of the Intergovernmental Panel on Climate Change; Cambridge University Press: Cambridge, UK, 2007.

22. United Nations Office for Disaster Risk Reduction (UNISDR). Available online: https://www.wto.org/ english/rese/statise/wts2016e/wts16toce.htm (accessed on 6 June 2017).

23. Li, J.Z.; Tan, S.M.; Wei, Z.Z. A new method of change point detection using variable fuzzy sets under environmental change. Water. Resour. Manag. 2014, 28, 5125-5138. [CrossRef]

24. Sun, Z.Y.; Zhang, J.Q.; Zhang, Q.; Hu, Y.; Yan, D.H.; Wang, C.Y. Integrated risk zoning of drought and waterlogging disasters based on fuzzy comprehensive evaluation in Anhui Province, China. Nat. Hazards 2014, 71, 1639-1657. [CrossRef]

25. Hao, L.; Zhang, X.Y.; Liu, S.D. Risk assessment to China's agricultural drought disaster in county unit. Nat. Hazards 2012, 61, 785-801. [CrossRef]

26. Huang, S.Z.; Chang, J.X.; Leng, G.Y.; Huang, Q. Integrated index for drought assessment based on variable fuzzy set theory: A case study in the Yellow River basin, China. J. Hydrol. 2015, 527, 608-618. [CrossRef]

27. Ganguli, P.; Reddy, M.J. Risk assessment of droughts in Gujarat using bivariate copulas. Water. Resour. Manag. 2012, 26, 3301-3327. [CrossRef]

28. Zhang, D.D.; Yan, D.H.; Lu, F.; Wang, Y.C.; Feng, C. Copula-based risk assessment of drought in Yunnan province. Nat. Hazards 2014, 75, 2199-2220. [CrossRef]

29. Guo, E.L.; Zhang, J.Q.; Ren, X.H.; Zhang, Q.; Sun, Z.Y. Integrated risk assessment of flood disaster based on improved set pair analysis and the variable fuzzy set theory in central Liaoning Province, China. Nat. Hazards 2014, 74, 947-965. [CrossRef]

30. Li, Q.; Zhou, J.Z.; Liu, D.H.; Tang, G.; Zou, Q. Disaster risk assessment based on variable fuzzy sets and improved information diffusion method. Hum. Ecol. Risk. Assess. 2013, 19, 857-872. [CrossRef]

31. Ouyang, W.; Yu, Y.Q.; Jin, J.L.; Zhou, Y.L.; Li, J.Q.; Liu, L.F. Risk assessment model of drought disaster based on information diffusion and bootstrap: a case study in Anhui. J. Catastrophol. 2015, 30, 228-234. (In Chinese)

32. Deng, M.H.; Chen, J.F.; Liu, G.Y.; Wang, H.M. Risk Assessment of Drought Based on IEAPP-IDM in Qujing, Yunnan Province, China. Adv. Meteorol. 2016, 2016, 7082467. [CrossRef] 
33. Wang, J.D.; Huang, C.F. Information diffusion method relevant in fuzzy information processing and its application. J. Northwest. Univ. 1992, 22, 383-392. (In Chinese)

34. Huang, C.F.; Wang, J.D. Fuzzy Information Optimization Technology and Its Application; University of Aeronautics \& Astronautics Press: Beijing, China, 1995. (In Chinese)

35. Huang, C.F.; Shi, Y. Towards Efficient Fuzzy Information Processing: Using the Principle of Information Diffusion; Physica-Verlag: Heidelberg, German, 2002; p. 99.

36. Saaty, T.L. Principia Mathematica Decernendi: Mathematical Principles of Decision Making; RWS Publications: Pittsburgh, PA, USA, 2009; p. 531.

37. Chen, S.Y. Theory and model of engineering variable fuzzy set-Mathematical basis for fuzzy hydrology and water resources. J. Dalian Univ. Technol. 2005, 45, 308-312. (In Chinese)

38. Zadeh, L.A. Fuzzy Sets; World Scientific: Singapore, 1965; Volume 8, pp. 338-353.

(C) 2017 by the authors. Licensee MDPI, Basel, Switzerland. This article is an open access article distributed under the terms and conditions of the Creative Commons Attribution (CC BY) license (http://creativecommons.org/licenses/by/4.0/). 